\title{
Two unrecorded alien plants in South Korea: Holosteum umbellatum L. and Asperugo procumbens L.
}

\author{
Hye-Jeong Lee, Su-Young Jung, Soo-Hyun Park, Seok-Min Yun ${ }^{1}$ and Jong-Cheol Yang* \\ Division of Forest Biodiversity and Herbarium, Korea National Arboretum, Pocheon, Gyeonggi 487-829, Korea \\ ${ }^{1}$ National Environment Division, Han River Basin Environmental office, Gyeonggi 465-731, Korea
}

(Received 24 September 2014; Accepted 17 November 2014)

\section{한국 미기록 외래식물: 산형나도별꽃, 갈퀴지치 \\ 이혜정 · 정수영 · 박수현 · 윤석민 ${ }^{1} \cdot$ 양종철* \\ 국립수목원 산림생물조사과, ${ }^{1}$ 한강유역환경청 자연환경과}

\begin{abstract}
Two alien plants Holosteum umbellatum L. and Asperugo procumbens L., belonging to Boraginaceae and Caryophyllaceae, respectively, have been first recorded in Hongseong-gun, Chungcheongnam-do and Incheon, South Korea. This initial investigation reports to inform the importance of detection and extermination of these potential weeds in surrounding areas. Furthermore, we report the morphological characteristic features of these two alien plants.
\end{abstract}

Keywords: Alien plants, Boraginaceae, Caryophyllaceae, Unrecorded genus.

적 요: 충청남도 홍성군과 인천광역시에서 각각 석죽과와 지치과의 미기록 외래식물 2 분류군을 발견하였다. 산 형나도별꽃(Holosteum umbellatum L.)과 갈퀴지치(Asperugo procumbens L.)는 종과 속이 국내에서는 처음으로 확인 되었다. 새롭게 침입한 외래식물들의 인지와 확산방지를 위한 기초 정보를 제공하고자 형태 및 특성을 보고 한다.

주요어: 외래식물, 지치과, 석죽과, 미기록 속

석죽과(Caryophyllaceae Juss.)는 전 세계적으로 북반구 에 넓게 분포하고, 종수는 약 86 속 2,200 여 분류군이 있다 (Lu et al., 2001; Hong and Choi, 2007). 국내에는 17속 64분 류군이 분포하며(Hong and Choi, 2007), 이번에 보고하는 석죽과 Holosteum 속은 국내에 처음 보고되는 속이다. 전 세계적으로 유럽과 지중해 지역부터 중앙아시아까지 4분 류군이 분포하며, 인접한 중국에는 1 분류군이 분포한다 (Lu and Rabeler, 2001).

Holosteum속의 특징은 산형화서를 이루며, 꽃잎은 끝이 고르지 않고 들쑥날쑥한 모양이다. 또한, 종자는 원통형 의 삭과이며, 축을 중심으로 배쪽이 납작한 모양으로 석 죽과의 근연 속들과 구별된다(Fernald, 1950; Gleason and Cronquist, 1991; Hickman, 1996).

\footnotetext{
*Author for correspondence: yangun@forest.go.kr
}

http://www.pltaxa.or.kr

Copyright (C) 2014 the Korean Society of Plant Taxonomists
지치과(Boraginaceae Juss.)는 온대 및 열대 지방에 널리 분포하며 특히 지중해 지역에 집중적으로 분포하고, 전 세 계적으로 약 156속 2,500여 분류군이 있다(Zhu et al., 1995; $\mathrm{Kim}, 2007)$. 국내에는 대략 15 속 27 분류군이 분포하는 것 으로 알려져 있다(Kim, 2007; Korean National Arboretum, 2014). 이번에 보고되는 Asperugo속은 국내에 처음 보고되 는 속으로 전 세계적으로 아시아(서남-서아시아)와 유럽 을 중심으로 1분류군만 분포한다(Zhu et al., 1995).

Asperugo속은 꽃받침 열편의 크기가 동일하지 않고, 좌 우에서 압착되어 조개모양처럼 되는 특징으로 지치과의 근연 속들과 구별된다(Fernald, 1950; Gleason and Cronquist, 1991; Hickman, 1996).

본 연구는 충청남도 홍성군에서 확인된 산형나도별꽃 (Holosteum umbellatum L.)과 인천광역시에서 확인된 갈퀴 지치(Asperugo procumbens L.) 2분류군에 대한 형태적인 특징을 기재하고, 새로운 국명과 국내 분포를 보고하는데 목적이 있다. 


\section{분류군의 기재}

Holosteum L., Sp. Pl. 88 (1753).

1 년생 초본이다. 줄기는 직립한다. 잎은 도피침형 또는 타원형이며, 탁엽은 없다. 꽃은 산형화서를 갖는다; 꽃받 침은 5 개; 꽃잎은 5 개이며, 불규칙한 거치가 있다; 수술은 3-5(또는 8-10)개이다; 자방은 1실로 배주는 다수이다; 주 두는 3(4 또는 5)개이다. 열매는 삭과이며 원통형, 상부에 6(8 또는 10)개의 거치가 생기고 밖으로 말린다; 종자의 개 수는 많으며, 축을 중심으로 배쪽이 납작한 모양이고, 잔 주름이 많다.

국명: 산형나도별꽃속(San-hyeong-na-do-byeol-kkoch-sok) 국외분포: 중앙아시아, 유럽, 지중해지역

\section{산형나도별꽃속(Holosteum)과 근연속의 속 검색표}

1. 암술대는 꽃받침의 개수와 같다 ... 개미자리속 Sagina

1. 암술대는 꽃받침의 개수보다 적다.

2. 열매의 열편은 2 개로 갈라지지 않으며, 암술대 개수 와 같다.

3. 다육성의 해안식물이며, 잎은 평평하고, 열매는 다
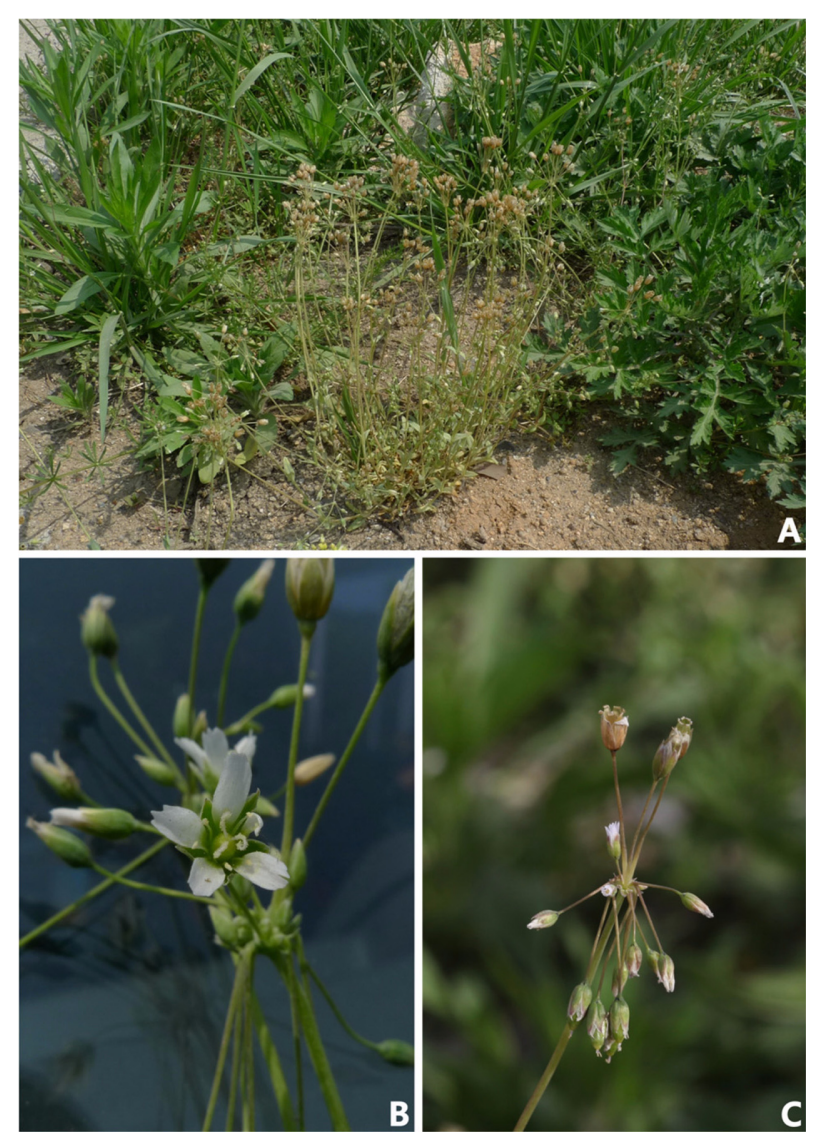

Fig. 1. Photographs of Holosteum umbellatum L. A. Habit; B. Flower; C. Fruit.
육질이다 갯별꽃속 Honkenya

3. 키가 작은 고산식물이며, 잎은 송곳모양이고, 열매 는 다육질이 아니다 ....... 나도개미자리속 Minuartia

2. 열매의 열편은 2 개로 갈라지고, 암술대 개수보다 2 배 많다.

4. 종자는 가종피가 있다 개벼룩속 Moehringia

4. 종자는 가종피가 없다.

5. 취산꽃차례, 원추꽃차례 또는 단생하고, 열매는 난형 또는 긴타원형이며, 종자는 신장형 또는 구 형이다 ……….................... 벼룩이자리속 Arenaria

5. 산형꽃차례이고, 열매는 원통형이며, 종자는 배 복성으로 납작한 형태이다

산형나도별꽃속 Holosteum

\section{Holosteum umbellatum L., Sp. Pl. 88 (1753).}

1 년생 초본이다. 줄기는 여러 개가 모여서 나오지만 가 지가 갈라지지 않으며; 대개 중간부분에는 엽병이 있는 샘털이 있다. 잎의 가장자리에 엽병이 있는 샘털이 있다; 기부 잎은 모여 나고, 도피침형 또는 장타원형으로 1-

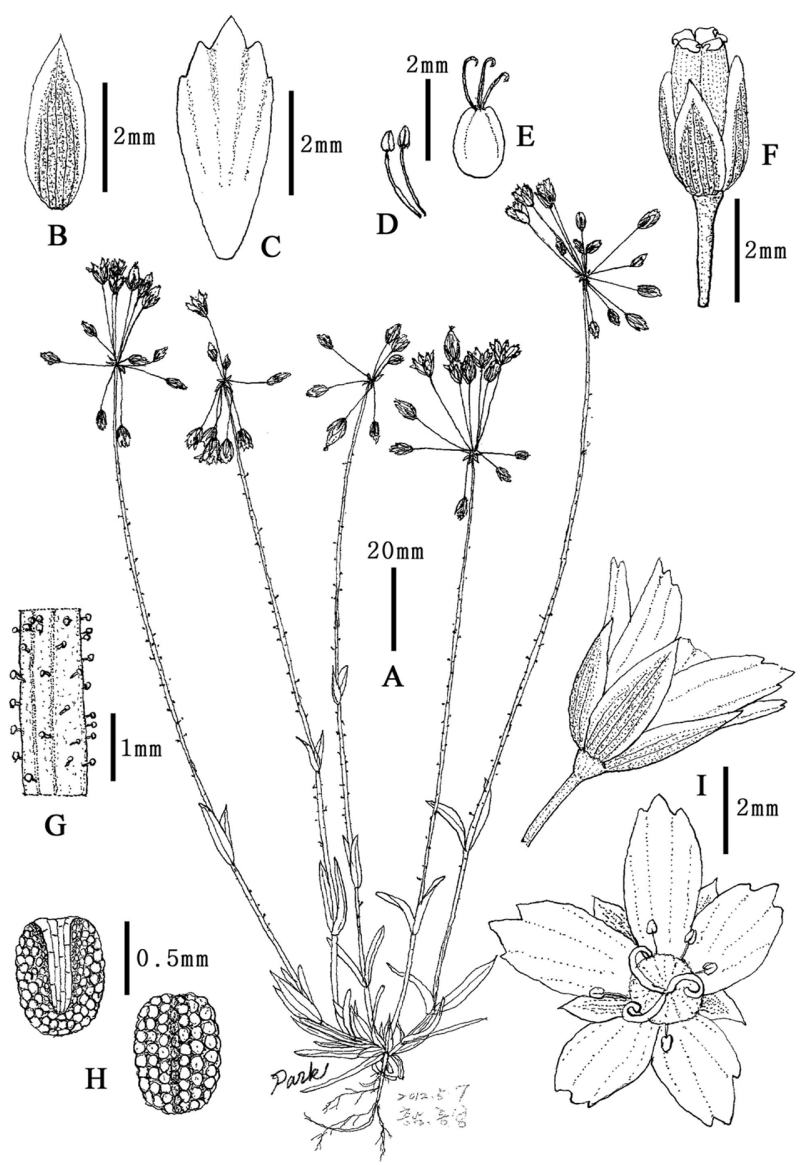

Fig. 2. Illustrations of Holosteum umbellatum L. A. Habit; B. Sepal; C. Petal; D. Stamens; E. Pistil; F. Pod; G. A part of a stem; H. Seeds; I. Flowers. 
$2.5 \mathrm{~cm}$ 이며, 흔히 엽병이 있다; 경생엽은 수가 적으며 엽 병이 없다. 꽃은 3-5월에 가느다란 화경이 나와 3-15개의 흰색 또는 담홍색 꽃이 피고, 종자성숙시기에는 $1.5-3 \mathrm{~cm}$ 까지 신장 한다; 꽃받침은 개화기에 $3 \mathrm{~mm}$ 이며; 꽃잎은 꽃 받침보다 약간 길다; 수술은 $3-5$ 개로 꽃잎 사이사이에 위 치한다. 열매는 4-6월에 성숙하는데 꽃받침이 윗부분부 터 강하게 밖으로 뒤집어 지면서 길이 $1 \mathrm{~mm}$, 붉은 갈색의 종자가 노출된다(Figs. 1, 2).

국명: 산형나도별꽃(San-hyeong-na-do-byeol-kkoch)

국외분포: 서남아시아(아프가니스탄, 카자흐스탄, 파키 스탄), 카슈미르, 인도, 러시아, 유럽.

관찰표본: Sangha-ri, Hongbuk-myun, Hongseong-gun, Chungcheongnam-do, South Korea, 7 May 2013, Park, S.H. 120157 (6 sheets: $\mathrm{KH})$.

\section{Asperugo L., Sp. Pl. 138. 1753.}

1 년생 초본이다. 줄기는 덩굴성으로 센털이 있다. 잎은 호생 한다; 엽병은 짧거나 없다. 꽃은 단생하거나 잎겨드 랑이에서 다발로 나온다; 꽃받침은 5 개로 갈라지고, 열편 사이에 2 개정도의 거치가 있으며, 종자결실기에는 더욱 커진다. 성숙된 꽃받침은 좌우에서 압착된 조개 모양으로 뚜렷한 그물맥을 가지며, 가장자리는 불규칙한 거치가 있 다; 꽃은 보라색 또는 흰색으로 화통이 연결되어 있고, 꽃 잎은 5 개로 갈라진다; 수술은 안쪽에 위치하며, 수술대는 매우 짧고, 꽃밥은 짧은 장타원형이다; 자방은 4실이다; 암술은 안쪽에 위치하며, 주두는 머리모양이다; 화탁은 송곳 모양이다. 열매는 견과이며 거의 평평하고 양쪽이 눌린 모양이다, 하얀색의 결절이 빽빽하게 있다; 종자는 세로로 서있으며 난형이다.

국명: 갈퀴지치속(Gal-kwi-ji-chi-sok) 국외분포: 아시아, 유럽

\section{갈퀴지치속(Asperugo)과 근연속의 속 검색표}

1. 견과는 타원체이다 ……..... 꽃받이속 Bothriospermum

1. 견과는 사면체 또는 렌즈형이다(때때로 거의 평평하다).

2. 수술은 화관 밖으로 돌출된다 ... 갯지치속 Mertensia

2. 수술은 화관 밖으로 나오지 않는다.

3. 견과는 4 개의 면이 있거나 3 개의 각이 있다 꽃마리속 Trigonotis

3. 견과는 렌즈형이다(때때로 거의 평평하다).

4. 꽃받침 열편은 거의 같으며, 결실기에 약간 커지 지만 조개껍데기 모양은 아니다

개꽃마리속 Myosotis

4. 꽃받침 열편은 서로 다르며, 결실기에 확연히 커 지고, 양면으로 납작한 조개껍데기 모양이다

갈퀴지치속 Asperugo
Asperugo procumbens L., Sp. Pl. 138. 1753.

1 년생 초본이다. 줄기는 속이 비어있으며, 옆으로 기면 서 다른 식물체들을 덮고 자라고, 전체적으로 갈고리 같 은 돌기가 있어 거칠다. 잎은 거치가 없고, 기부에서는 대 생하지만 위쪽에서는 호생하며, 상부 잎에는 잎자루가 없 다. 길이는 $2-7 \mathrm{~cm}$ 정도로 타원형 또는 도피침형이다. 꽃 은 5-7월에 잎겨드랑이에서 나오며; 포엽은 있거나 없다; 꽃은 파란색 또는 보라색이다; 꽃받침은 5 개로 갈라지며, 개화기때 길이는 2-3 mm이지만 결실기에는 길이 $5-8 \mathrm{~mm}$, 너비 10-15 mm정도로 커진다, 열편마다 1-2개의 거치가 있으며 견과를 둘러싸고 있다. 열매는 6-9월에 익으며, 길 이 2-3 mm의 견과로 2-4개가 있고, 양쪽이 눌린 납작한 모 양의 장상형 또는 난형이고, 윤기가 나며, 표면에 작은 혹 들이 있다(Figs. 3, 4).

\section{국명: 갈퀴지치(Gal-kwi-ji-chi)}

국외분포: 북인도, 카슈미르, 카자흐스탄, 키르기스스 탄, 몽골, 네팔, 러시아, 타지키스탄, 투르크메니스탄, 우 즈베키스탄, 서남-서아시아, 유럽, 북-서북아프리카.

관찰표본: Bukhang 8 quay, Inchon Harbor, Inchon, South Korea, 4 Jun. 2010, Park, S.H. 100806 (7 sheets: KH).

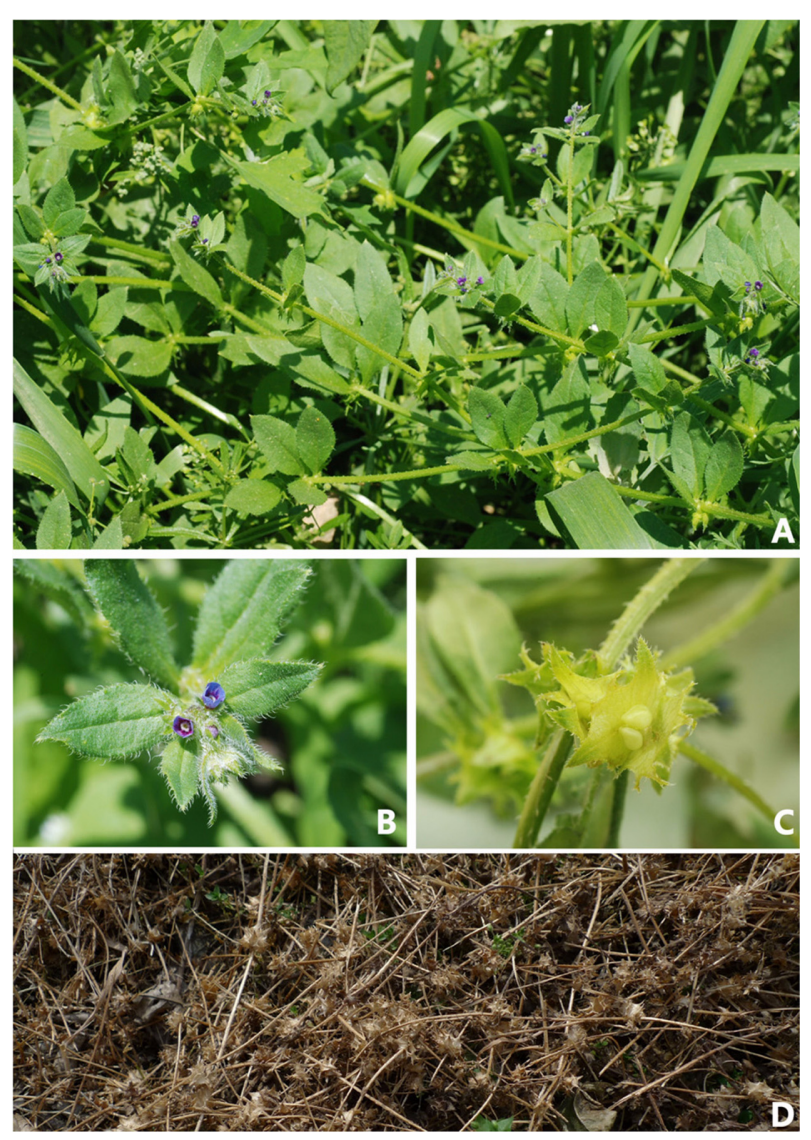

Fig. 3. Photographs of Asperugo procumbens L. A. Flowering habit; B. Flower; C. Fruit; D. Fruiting habit. 


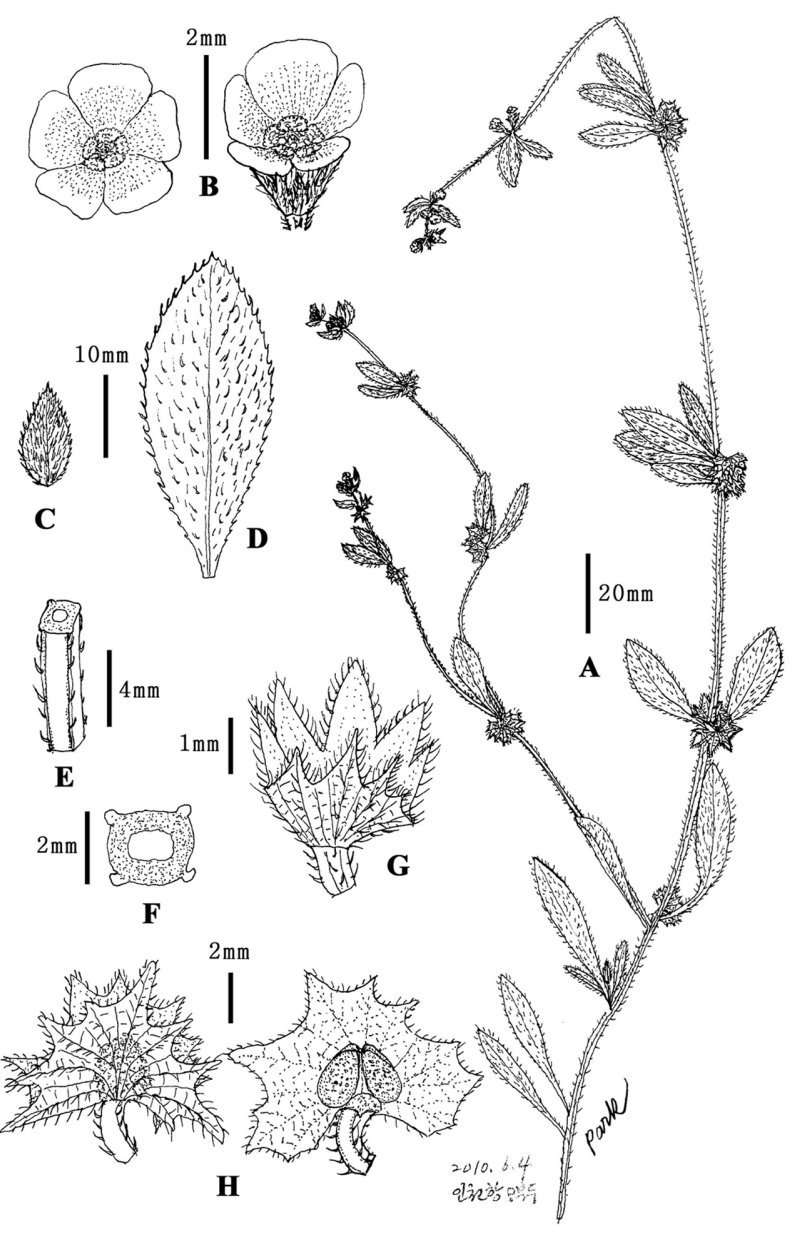

Fig. 4. Illustrations of Asperugo procumbens L. A. Habit; B. Flowers; C. Bract; D. Cauline leaf; E. A part of stem; F. Transverse section of a stem; G. Calyx at the flowering season; H. Fruits.

\section{고 찰}

국내에 새롭게 분포가 확인된 산형나도별꽃(Holosteum umbellatum L.)은 2009년부터 6년간 충청남도 홍성군 홍북 면 상하리 용봉산 부근의 도로 양옆 화단과 길가 주변으로 분포가 확인되었다. 최초 발견당시 약 $0.5 \mathrm{~m}$ 의 너비로 $2 \mathrm{~km}$ 구간에 걸쳐 도로 가장자리를 따라 500여 개체 이상이 지 속적인 분포가 나타났다. 주변식생은 상층에 상수리나무 (Quercus acutissima Carruth.), 신갈나무(Q. mongolica Fisch. ex Ledeb.), 찔레꽃(Rosa multiflora Thunb.), 산딸기(Rubus crataegifolius Bunge), 하층에 댕댕이덩굴[Cocculus trilobus (Thunb.) DC.], 메꽃[Calystegia sepium var. japonicum (Choisy) Makino], 고사리[Pteridium aquilinum var. latiusculum (Desv.) Underw. ex A.Heller], 개망초[Erigeron annuus (L.) Pers.], 쑥 (Artemisia indica Willd.), 왕고들빼기(Lactuca indica L.), 박주 가리[Metaplexis japonica (Thunb.) Makino], 뽀리뱅이 [Youngia japonica (L.) DC.], 냉이[Capsella bursa-pastoris (L.) L.W.Medicus], 지칭개(Hemistepta lyrata Bunge), 큰개불알풀
(Veronica persica Poir.) 등 일조량이 풍부한 장소를 선호하 는 식물들이 함께 혼생하고 있다. 현재는 도로공사에 따른 생육지 일부가 소실되었으나, 개체 당 종자결실수가 많으 며 종자의 크기가 약 $1 \mathrm{~mm}$ 로 작고 가벼워 주변지역으로 지 속적인 확산이 예상되며, 일부 주변지역으로 확산이 진행 되고 있어서 완전히 소멸될 가능성은 낮아 보인다.

유입경로는 홍성군일대에 많은 목장지역이 위치하고 있어서 수입된 목초 등 물자이동에 의한 원인이 클 것으 로 추측된다. 개화기와 결실기가 3 월부터 이루어지기 때 문에 주변 식물들과 경쟁에서는 높은 경쟁력을 가지고 있 으나, 피해나 문제발생에 대해서는 아직 확인된바 없다. 하지만, 높은 확산력에 따른 분포지의 대규모 발생 또는 초기 식생 점유와 같은 문제발생이 예상된다. 그에 따라 예상경로에 따른 주변지역 확산예측과 관리에 대한 계획 이 진행되어져야 할 것으로 보인다.

갈퀴지치(Asperugo procumbens L.)는 인천광역시 중구 항동 7 가 인천항 8 부두의 곡물저장고주변 햇빛이 잘 드는 노지에서 확인하였다. 2010년 처음 생육을 확인하였으며, 그 지역 담당자들에게 문의한 결과 이전에도 출현한 것으 로 전해진다. 3년 후 동일장소의 모니터링을 실시한 결과 2010년 결과보다 분포지역이 더 확대되어, 주변 도로화단 까지 확산되어 있는 것을 확인하였다. 약 $10 \times 30 \mathrm{~m}$ 의 장소 에서 50 개체 정도가 분포하고 있었고, 주변에는 좀명아주 (Chenopodium ficifolium Smith), 새포아풀(Poa annua L.), 말 냉이(Thlaspi arvense L.), 뚝새풀(Alopecurus aequalis Sobol.), 닭의덩굴[Fallopia dumetorum (L.) Holub], 털쇠무릎 (Achyranthes fauriei H.Lév. \& Vaniot), 족제비쑥(Matricaria matricariodes Porter), 쇠별꽃 [Stellaria aquatica (L.) Scop.], 별 꽃 [S. media (L.) Vill.], 닭의장풀(Commelina communis L.), 개 소시랑개비(Potentilla supina L.) 등의 식물들이 함께 생육 하고 있다. 갈퀴지치에 의한 우려되는 상황은 주변 식물을 덮고 자라는 특성으로 초본식물들을 피압하여 생육저하, 고사 등이 확인되며, 대규모 확산시 심각한 문제가 야기될 것으로 예상된다. 주변지역이 대부분 포장된 도로지역으 로 우려되는 확산은 없을 것으로 판단되지만 인근에 월미 공원이 조성되어 있어서 차량이동, 탐방객 등과 같은 인위 적인 요인이나 자연적으로도 확산될 가능성은 충분히 예 상되므로 계속적인 모니터링이 필요하다.

유입경로는 항만을 통해 들어오는 수입곡물에 혼입되어 곡물창고 주변에 유입된 것으로 보이며, 이밖에도 이 지역 은 도깨비가지(Solanum carolinense L.), 털까마중(Solanum sarrachoides Sendtn.), 우단담배풀(Verbascum thapsus L.) 등 외래식물의 출현율이 높다.

산형나도별꽃은 꽃이 자생종인 별꽃과 유사하고 산형 화서를 가지는 특징을 따라 명명하였으며, 갈퀴지치는 전 체적으로 갈고리 같은 돌기가 있으며, 특히 꽃이 진 뒤 종 자를 감싸고 있는 꽃받침의 열편모양이 갈퀴와 비슷해 이 를 고려하여 명명하였다. 


\section{사 사}

이 논문은 국립수목원 귀화식물의 산림내 침입유형 평 가 및 모니터링 과제의 일환(KNA1-1-12, 13-2)으로 수행 되었습니다.

\section{인용문헌}

Fernald, M. L. 1950. Gray's manual of botany, 8th ed. D. Van Nostrand Co., New York, USA. Pp. 611-629, 1195-1205.

Gleason, H. A. and A. Cronquist. 1991. Manual of Vascular Plants of Northeastern United States and Adjacent Canada. Second Edition. New York Botanical Garden, Bronx, NY, USA. Pp. 112-117, 419-422.

Hickman, J. C. 1996. The Jepson manual: Higher plants of California. University of California Press, Berkeley. Pp. 366-369, 475-482.

Hong, S. P. and K. Choi. 2007. Caryophyllaceae Juss. In Genera of Vascular Plants of Korea. Park, C.-W. (ed.), Academy Publishing Co., Seoul. Pp. 310-333.
Kim, Y. D. 2007. Boraginaceae Juss. In Genera of Vascular Plants of Korea. Park, C.-W. (ed.), Academy Publishing Co., Seoul. Pp. 798-807.

Korea National Arboretum. 2014. Korean Plant Names Index. Retrieved Aug. 18, 2014, http://www.nature.go.kr/newkfsweb/ $\mathrm{kfs} / \mathrm{idx} /$ SubIndex.do?orgId=kpni\&mn=KFS_29.

Lu, D. Q. and R. K. Rabeler. 2001. Holosteum. In Flora of China. Vol. 6. Wu, Z. Y. and P. H. Raven (eds.). Science Press and Missouri Botanical Garden Press, Beijing and St. Louis. Pp. 40.

Lu, D. Q., Z. Y. Wu, L. H. Zhou, S. L. Chen, M. G. Gilbert, M. Lidén, J. McNeill, J. K. Morton, B. Oxelman, R. K. Rabeler, M. Thulin, N. J. Turland and W. L. Wagner. 2001. Caryophyllaceae. In Flora of China. Vol. 6. Wu, Z. Y. and P. H. Raven (eds.). Science Press and Missouri Botanical Garden Press, Beijing and St. Louis. Pp. 1-113.

Zhu, G., H. Riedl and R. V. Kamelin. 1995. Asperugo. In Flora of China. Vol. 16. Wu, Z. Y. and P. H. Raven (eds.). Science Press and Missouri Botanical Garden Press, Beijing and St. Louis. Pp. 417. 